\title{
The University of Zurich (UZH) Hosts the Inaugural Dorothy Crowfoot Hodgkin Symposium
}

\author{
Nathaniel S. Finney
}

\begin{abstract}
On Friday, May 5th, 2006, the Organic Chemistry Institute hosted the inaugural Dorothy Crowfoot Hodgkin Symposium at the University of Zurich. The Symposium, which will be held annually, will showcase the work of premier female researchers from all scientific disciplines. Dr. Jenny Glusker presented a broad and informative retrospective of Hodgkin's life, after which Prof. Anna Bernardi provided an overview of her group's work in the synthesis and biological evaluation of glycomimetics. Dr. Jennifer Albaneze-Walker described work carried out under her supervision at Merck on the development of PDE IV inhibitors, and Prof. Lia Addadi unified the preceding themes in presenting her work on antibody recognition of cholesterol-related structures.
\end{abstract}

Keywords: Cholesterol binding · Crystallography · Dorothy Crowfoot Hodgkin Symposium · Glycosyl derivatives . Phosphodiesterase inhibitors

On Friday, May 5th, 2006, the Organic Chemistry Institute hosted the inaugural Dorothy Crowfoot Hodgkin Symposium at the University of Zurich. The Symposium, which will be held annually, will showcase the work of premier female researchers from all scientific disciplines. Organized by Prof. Kim Baldridge, it is modeled after the successful Maria Goeppert-Mayer Symposia that she has organized through the San Diego Supercomputer Center for more than a decade. (See http://www.oci.unizh.ch/diversa/dch/for further information)

\footnotetext{
${ }^{\star}$ Correspondence: PD Dr. N.S. Finney

University of Zurich

Institute of Organic Chemistry

Winterthurerstrasse 190

$\mathrm{CH}-8057$ Zurich

Tel.: + 41446354283

E-Mail: finney@oci.unizh.ch
}

Dorothy Crowfoot Hodgkin (19101994) received the Nobel Prize in Chemistry in 1964, "for her determinations by $\mathrm{X}$-ray techniques of the structures of important biochemical substances" (from the Nobel citation). This accomplishment was emblematic of her long-standing fascination with the structure of the molecules of life, which led to the first structure solutions for cholesterol, vitamin B12, lactoglobulin, penicillin, ferritin, the tobacco mosaic virus and insulin. As part of the efforts, she made fundamental contributions to methods for indexing and assigning intensities to X-ray diffraction patterns. In addition to her remarkable scientific career she was an exemplary teacher and mentor, and left as a legacy a sizable group of successful, dedicated and grateful younger scientists.

The first speaker of the Symposium was one of Hodgkin's former students, Dr. Jenny Glusker (Basic Science Division, Fox Chase Cancer Center). Rather than discussing her own distinguished career as a crystallographer, Dr. Glusker presented a broad and informative retrospective of Hodgkin's life. Following Hodgkin from her early work with Bernal to her independent appointment at Oxford, election to the Royal Society and receipt of the Nobel Prize covered only the first half of her career (Which did include the memorable quote from J.W. Cornforth, also a Nobel Laureate, "If penicillin turns out to have the beta-lactam structure I shall give up chemistry and grow mushrooms."). Hodgkin remained professionally active

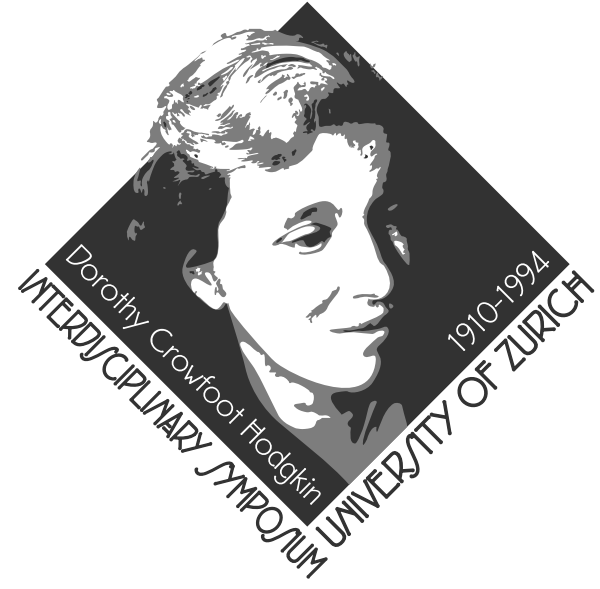

almost her entire life, revisiting and revising the crystal structure of insulin as late as 1988 and giving her first U.S. lecture tours in the early 1990 s.

Prof. Anna Bernardi (Department of Organic Chemistry, University of Milan) next provided an overview of her group's work in the synthesis and biological evaluation of glycomimetics. While it is well established that oligosaccharides play a key role in mediating biological function, synthetic methods have only recently begun to permit the facile preparation of biologically active carbohydrate mimics. Prof. Bernardi showcased three important facets of her recent work: the use of readily-accessible cyclohexane derivatives as replacements for 


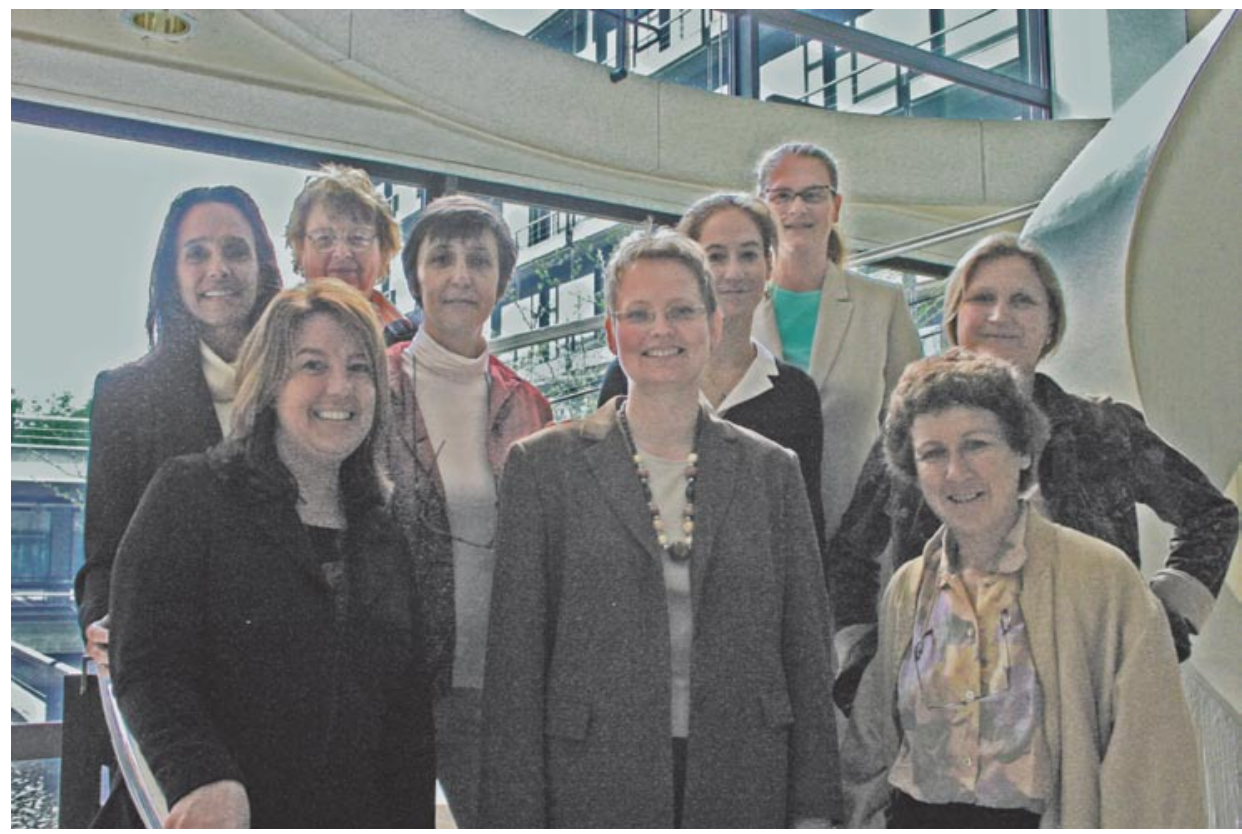

Participants in the inaugural Dorothy Crowfoot Hodgkin Symposium (left to right): front row - Dr. Tracey Burr, Dr. Wibke Sudholt, Prof. Lia Addadi; middle row - Prof. Kim Baldridge, Prof. Anna Bernardi, PD Dr. Eva Freisinger, Prof. Julia Fritz-Steuber; back row - Dr. Jenny Glusker, Dr. Jennifer Albaneze-Walker.

more complex sugars; the structural importance of inter-chain hydrophic interactions in analogs of branched oligosaccharides; and a remarkable Staudinger ligation reaction for the stereoselective conversion of $\alpha$-glycosyl azides to the corresponding $\alpha$ amido derivatives - one of the only methods for the preparation of such $\mathrm{N}$-linked glycocomimetics.

Continuing the discussion of synthetic chemistry as a tool for, ultimately, controlling biological function, Dr. Jennifer Albaneze-Walker (Synthetic Chemistry Department, Schering-Plough) described work carried out under her supervision at Merck on the development of PDE IV inhibitors. This enzyme is important in the inflammatory cascade, regulating the production of TNF- $\alpha$, and is also relevant in a number of other ailments. Emphasis was placed on the distinction between discovery synthesis, where the focus is finding a new biologically active molecule, and process chemistry, where efficiency, cost and impurity profile are of paramount importance. This distinction was illustrated with the synthesis of two naphthyridone-based PDE IV inhibitors. In each case, an initial discovery route of greater than ten transformations was contracted to a robust, scalable synthesis of six or fewer steps. Both syntheses relied on key Pd-catalyzed coupling reactions, and strategies for eliminating transition metal contaminants were prominently featured.

Prof. Lia Addadi (Department of Structural Biology, Weizmann Institute) unified the preceding themes in presenting her work on antibody recognition of cholesterol-related structures. Steroid chemistry was significantly transformed by Hodgkin's determination of the structure of cholesterol, which had previously remained elusive to organic chemists. Relying on biological systems for the synthesis of cholesterolbinding antibodies, Prof. Addadi described a long-term effort to discover and apply antibodies that can recognize cholesterol and cholesterol-containing cellular structures. Based on the ability to raise antibodies against crystalline cholesterol, hybrid reagents have now been developed to fluorescently label cholesterol in lipid bilayers, image arteriosclerotic plaque in animal models, and possibly even visualize 'lipid rafts' on the surface of cells.

The Symposium was followed by an apéro and a poster session that included more than 30 participants. The OCI would like to express its appreciation to the KGF and Schering-Plough for generous financial support, and the chemistry community of Zürich for enthusiastic participation. Additional OCI-hosted events in 2006 will include a Symposium in Honor of Prof. Heinz Heimgartner on 9. June and the Siegfried Medal Symposium on 21. September. (See http://www.oci.unizh.ch for details)

Received: May 12, 2006 